\title{
Local and systemic influence of toxic levels of airborne ozone on the inflammatory response in rats
}

\author{
Małgorzata Chmielewska-Krzesińska ${ }^{\bowtie}$, Krzysztof Wąsowicz \\ Department of Pathophysiology, Forensic Veterinary Medicine and Administration, Faculty of Veterinary Medicine, University \\ of Warmia and Mazury in Olsztyn, Olsztyn, Poland \\ malgorzata.chmielewska@uwm.edu.pl
}

Received: April 27, $2020 \quad$ Accepted: September 9, 2021

\begin{abstract}
Introduction: Ozone is not harmful itself; however, it directly oxidises biomolecules and produces radical-dependent cytotoxicity. Exposure to ozone is by inhalation and therefore the lungs develop the main anti-inflammatory response, while ozone has an indirect impact on the other organs. This study investigated the local and systemic effects of the ozone-associated inflammatory response. Material and Methods: Three groups each of 5 Wistar Han rats aged 6 months were exposed for $2 \mathrm{~h}$ to airborne ozone at $0.5 \mathrm{ppm}$ and a fourth identical group were unexposed controls. Sacrifice was at $3 \mathrm{~h}$ after exposure for control rats and one experimental group and at $24 \mathrm{~h}$ and $48 \mathrm{~h}$ for the others. Lung and liver samples were evaluated for changes in expression of transforming growth factor beta 1 , anti-inflammatory interleukin 10, pro-inflammatory tumour necrosis factor alpha and interleukin 1 beta and two nuclear factor kappa-light-chain-enhancer of B cells subunit genes. Total RNA was isolated from the samples in spin columns and cDNA was synthesised in an RT-PCR. Expression levels were compared to those of glyceraldehyde3-phosphate dehydrogenase (GAPDH) and analysed statistically. Results: All variables changed non-linearly over time comparing experimental groups to the control. Conspicuous expression changes in the subunit genes and cytokines were observed in both evaluated organs. Conclusion: Locally and systemically, inflammation responses to ozone inhalation include regulation of certain genes' expression. The mechanisms are unalike in lungs and liver but ozone exerts a similar effect in both organs. A broader range of variables influential on ozone response should be studied in the future.
\end{abstract}

Keywords: ozone, free radicals, inflammatory response, respiratory tract inflammation, rat.

\section{Introduction}

Ozone is a multifaceted molecule. It exerts a harmful effect as an element of photochemical smog (5) and by-product of the operation of laser printers, copy machines, and similar devices (10). Ozone is a reactive molecule readily oxidising sensitive organic molecules. Due to its intense smell, it is detectable in concentrations well below those causing acute toxicity. However, low concentrations even below the detection limit are harmful long-term and are associated with the occurrence of respiratory tract inflammation and bronchial asthma (3). There is also a link between ozone pollution and ailments of organs not directly exposed to environmental ozone, atherosclerosis being an example of such a condition (15). Ozone entering the body via the respiratory route cannot reach internal organs in its native form. It reacts readily with biomolecules, causing lipid peroxidation and damage to other molecules. Questions for research to answer are if, why and how inhaled ozone exerts its systemic effect. The possible mechanism is the systemic action of molecules formed locally as ozone damage to airways.

On the other hand, ozone has various applications with different beneficial effects in the alternative treatment of certain ailments (1), also in veterinary medicine $(2,12)$. Available data show that the efficacy of ozone treatment may not be attributable merely to the placebo effect and the mechanisms of its effect must be investigated (16). To make the issue more complicated, there are reports showing that ozone may exert an antiinflammatory effect on an organism in low concentrations and protect it from the harmful influence of higher concentrations (8). The most probable explanation is the well-known phenomenon of hormesis, which is exactly this: the protective effect of low-level exposure against subsequent high-level exposure. However, the exact molecular mechanism needs to be elucidated.

An inflammatory response is triggered by receptors sensing molecules generated in response to tissue 
damage called damage-associated molecular patterns. Toll-like receptors (TLRs) play the major role in triggering the response to these molecules. Activation of TLRs leads to nuclear translocation of the nuclear factor kappa-light-chain-enhancer of activated B cells (NF- $\mathrm{B}$ ) transcription factor, induction of expression of pro-inflammatory interleukins such as tumour necrosis factor alpha (TNF- $\alpha$ ) and interleukin 1 (IL-1) and initiation of inflammation. However, inflammation is a complex process, the essence of which is the interplay of pro-inflammatory and anti-inflammatory factors which control its intensity. Anti-inflammatory factors are therefore equally important for determining the inflammation course. The well-known interleukins with anti-inflammatory properties are interleukin 10 (IL-10) and transforming growth factor beta (TGF- $\beta)(9,11)$. TGF- $\beta$ is one of the anti-inflammatory factors which targets NF- $\kappa \mathrm{B}$.

Some of these factors (for example TNF- $\alpha$, IL-1 and IL-10) are synthesised and released upon the activation of inflammation-associated cells. The expression of these genes would seem to increase with their inflammation-associated release. Other substances such as NF- $\kappa$ B and TGF- $\beta$ are synthesised in the inactive form and activated when needed. Whether their expression level remains unchanged in the course of the inflammatory response or changes due to some regulatory mechanism is a matter of interest (6).

This study investigated the local and systemic effects of ozone associated with an inflammatory response. The experimental setup involved exposing rats to high levels of ozone and then assaying the expression levels of two NF- $\kappa \mathrm{B}$ subunit genes (NFKB1 coding the p100 and NFKB2 coding the p105 subunit), as well as genes of pro-inflammatory (TNF- $\alpha$ and IL-1 $\beta$ ) and anti-inflammatory (IL-10 and TGF- $\beta 1$ ) interleukins in the lungs (as the organ directly exposed to airborne ozone) and the liver (an organ distant anatomically and functionally from the airways). The changes in the interleukin expression levels were studied for over
48 hours following the exposure to evaluate the rise and fall of the inflammatory response.

\section{Material and Methods}

Male Wistar Han rats numbering 20 and aged 6 months were used for the study. The animals were divided into four groups of 5 animals each. Group I was the control. The remaining three groups were exposed for $2 \mathrm{~h}$ to airborne ozone at a concentration of $0.5 \mathrm{ppm}$ in a dedicated exposure chamber. After exposure, the animals were sacrificed with a fatal dose of isoflurane administered in an anaesthetic chamber. Animals of group II were sacrificed $3 \mathrm{~h}$ after the exposure, animals of group III after 24 hours and those of group IV after $48 \mathrm{~h}$. The rats of group I were sacrificed in the same manner. Samples of the lungs and liver were taken, fixed in RNAlater Stabilization Solution (Ambion, Austin, TX, USA) and stored at $-80^{\circ} \mathrm{C}$ until required for assays. Total RNA was isolated with an RNAEasy Kit (Qiagen, Hilden, Germany) according to the manufacturer's instructions. Total RNA concentration and quality were determined using a NanoVue Plus Spectrophotometer (GE Healthcare, Chicago, IL, USA). The integrity of RNA samples was verified with agarose electrophoresis.

Complementary DNA was synthesised with a RevertAid First Strand cDNA Synthesis Kit (Thermo Fisher Scientific, Waltham, MA, USA) with $2 \mu \mathrm{g}$ of total RNA for each sample. The real-time RT-PCR was performed in a 7500Fast thermocycler (Applied Biosystems, Foster City, CA, USA). The reaction mixture was composed as follows: $1 \mu \mathrm{L}$ of diluted (1:2) RT product, $10 \mu \mathrm{L}$ of qPCR SYBR Select Master Mix (Thermo Fisher Scientific), $1 \mu \mathrm{L}$ of primer mix (5 $\mu \mathrm{M}$ each) and $8 \mu \mathrm{L}$ of nuclease-free water. The temperature cycle profile was as follows: $10 \mathrm{~min}$ at $95^{\circ} \mathrm{C}$ followed by 40 cycles at $95^{\circ} \mathrm{C}$ for $15 \mathrm{~s}$ and $60^{\circ} \mathrm{C}$ for $1 \mathrm{~min}$. Each sample was subjected to these procedures in triplicate.

Table 1. Genes and sequences of primers used in the experiment

\begin{tabular}{|c|c|c|c|c|c|}
\hline Gene name & GenBank number & & $5^{\prime} \rightarrow 3^{\prime}$ & $\begin{array}{l}\text { Exon } \\
\text { junction }\end{array}$ & $\begin{array}{l}\text { Product } \\
\text { length (bp) }\end{array}$ \\
\hline \multirow{2}{*}{$\begin{array}{l}\text { Glyceraldehyde-3- } \\
\text { phosphate dehydrogenase } \\
\text { (GAPDH) }\end{array}$} & \multirow{2}{*}{ NM_017008.4 } & Forward & CATGGCCTTCCGTGTTCCTA & & \multirow[t]{2}{*}{74} \\
\hline & & Reverse & ACTTGGCAGGTTTCTCCAGG & $825 / 826$ & \\
\hline \multirow{2}{*}{$\begin{array}{l}\text { Nuclear factor of kappa- } \\
\text { light-chain--enhancer in B - } \\
\text { cells } 1(\mathrm{NF}-\kappa \mathrm{B} 1)\end{array}$} & \multirow{2}{*}{ NM_001276711.1 } & Forward & GCCAACTGGCAGGTATTTGAC & $2694 / 2695$ & \multirow[t]{2}{*}{117} \\
\hline & & Reverse & TTGCAGCCTCGTGTCTTCTG & & \\
\hline \multirow{2}{*}{$\begin{array}{l}\text { Nuclear factor of kappa- } \\
\text { light-chain--enhancer in B = } \\
\text { cells } 2, \mathrm{p} 49 / \mathrm{p} 100(\mathrm{NF}-\kappa \mathrm{B} 2)\end{array}$} & \multirow{2}{*}{ NM_001008349.1 } & Forward & TGGTACAGAGCGGTAAGAGTG & $2326 / 2327$ & \multirow[t]{2}{*}{134} \\
\hline & & Reverse & TCTGTCTCAGCCAGGCTACC & & \\
\hline \multirow{2}{*}{ Interleukin $10(\mathrm{IL}-10)$} & \multirow{2}{*}{ NM_012854.2 } & Forward & TGCGACGCTGTCATCGATTT & $379 / 380$ & \multirow[t]{2}{*}{129} \\
\hline & & Reverse & TGGCCTTGTAGACACCTTTGT & & \\
\hline \multirow{2}{*}{$\begin{array}{l}\text { Tumour necrosis factor } \\
\text { alpha (TNF- } \alpha)\end{array}$} & \multirow{2}{*}{ NM_012675.3 } & Forward & ATGGGCTCCCTCTCATCAGT & & \multirow[t]{2}{*}{106} \\
\hline & & Reverse & GCTTGGTGGTTTGCTACGAC & $433 / 434$ & \\
\hline \multirow{2}{*}{ Interleukin 1beta (IL-1 $\beta)$} & \multirow{2}{*}{ NM_031512.2 } & Forward & CCTATGTCTTGCCCGTGGAG & & \multirow[t]{2}{*}{82} \\
\hline & & Reverse & AGAGGACGGGCTCTTCTTCAA & $354 / 355$ & \\
\hline \multirow[t]{2}{*}{$\begin{array}{l}\text { Transforming growth factor } \\
\text { beta } 1 \text { (TGF- } \beta 1)\end{array}$} & \multirow[t]{2}{*}{ NM_021578.2 } & Forward & CTGCTGACCCCCACTGATAC & & \multirow[t]{2}{*}{94} \\
\hline & & Reverse & AGCCCTGTATTCCGTCTCCT & $779 / 780$ & \\
\hline
\end{tabular}


The expression of two NF- $\kappa \mathrm{B}$ subunit genes as well as TNF- $\alpha$, IL- $1 \beta$, IL- 10 and TGF- $\beta 1$ genes was studied with real-time RT-PCR using glyceraldehyde-3phosphate dehydrogenase as a reference gene (Table 1). All primer sequences were designed using PrimerBLAST and manufactured as custom order Pure and Simple Primers (Sigma-Aldrich, St. Louis, MO, USA). No secondary structures were detected nor pseudogenes amplified. Reactions without the template were used as negative controls.

Statistical differences in gene expression between group I (control) and the ozone-exposed groups II, III and IV (respectively sacrificed at $3 \mathrm{~h}, 24 \mathrm{~h}$ and $48 \mathrm{~h}$ ) were assessed by one-way ANOVA followed by Dunnett's multiple comparison test in cases when the data were normally distributed or by the non-parametric KruskalWallis test followed by Dunn's test when the data were not normally distributed. The data are presented as boxes and whiskers indicating mean and standard deviation.

\section{Results}

Changes in interleukin expression in the lungs. The study showed changes in the expression of selected genes in lungs (Fig. 1).
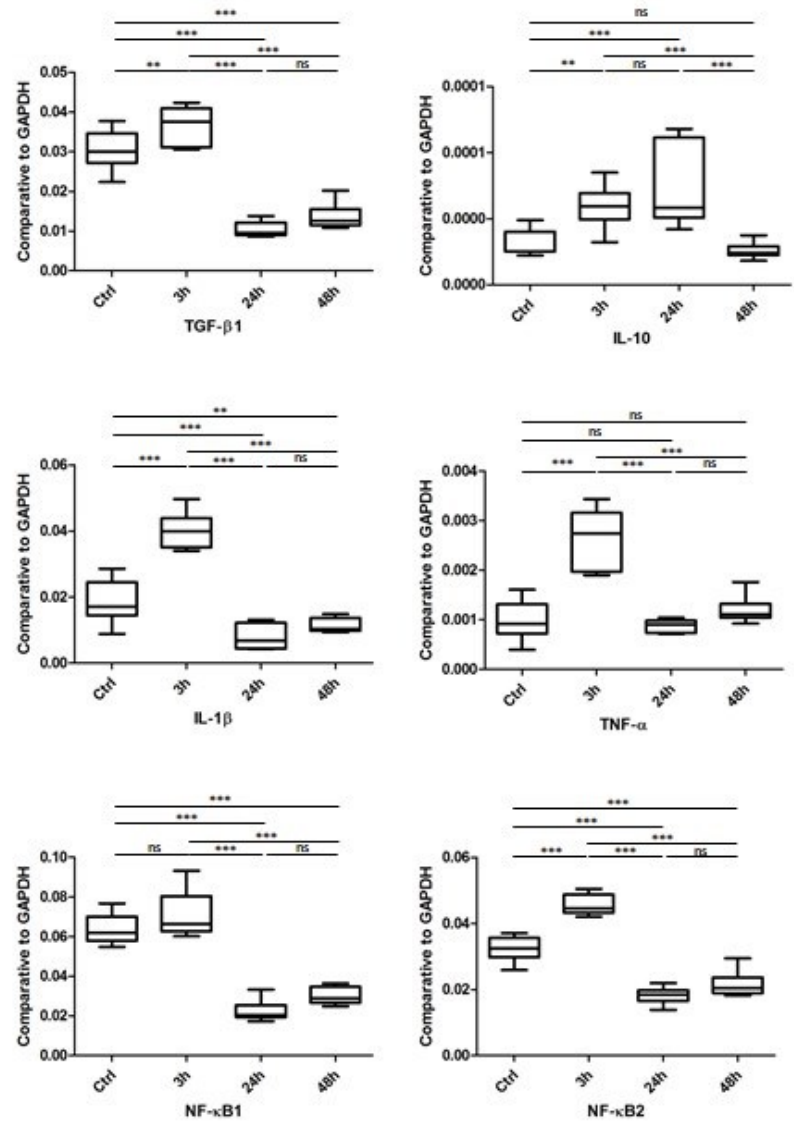

Fig. 1. Changes in interleukin expression in the lungs. Ctrl - Group I (control); $3 \mathrm{~h}$ - Group II; $24 \mathrm{~h}$ - Group III; $48 \mathrm{~h}$ - Group IV. Significance levels are indicated with asterisks: $* \mathrm{P} \leq 0.05 ; * * \mathrm{P} \leq 0.01$; $* * * \mathrm{P} \leq 0.001$. Ns - not statistically significant
Surprisingly, the expression of TGF- $\beta 1$ followed the expression change pattern characteristic for proinflammatory interleukins. Its expression level rose in Group II at $3 \mathrm{~h}$ and dropped dramatically to levels lower than in the control group in Group III at 24 and Group IV at $48 \mathrm{~h}$ post-exposure. Changes in the expression of IL-10 were significantly different from the changes in the expression of pro-inflammatory interleukins. The expression level of IL-10 was the highest $3 \mathrm{~h}$ after ozone exposure (Group II) and this level changed slightly up to $24 \mathrm{~h}$ (Group III). IL-10 gene expression diminished $48 \mathrm{~h}$ after ozone exposure (Group IV) to the level in the control group (Group I).

The expression of IL- $1 \beta$ rose sharply 3 hours after ozone exposure and reached twice the level in the control animals. Surprisingly, $24 \mathrm{~h}$ after exposure, the IL-1 $\beta$ expression also dropped sharply, declining to only $50 \%$ of the expression level in the control group. In the $48 \mathrm{~h}$ group, the expression level was higher than in the $24 \mathrm{~h}$ group but still lower than in the control animals. Changes in TNF- $\alpha$ expression followed roughly the same pattern with the difference that at $24 \mathrm{~h}$ the expression level was slightly lower and at $48 \mathrm{~h}$ slightly higher than in the control animals. The expression changes of the two NF- $\mathrm{B}$ subunit genes in the lung were similar, albeit different as regards their extents. The expression level increased up to $3 \mathrm{~h}$ after exposure, then decreased markedly up to $24 \mathrm{~h}$, but was higher (while still much lower than in the control group) $48 \mathrm{~h}$ after exposure.

Changes in interleukin expression in the liver. The study also showed changes in the expression of selected genes in the liver (Fig. 2). The expression of TGF- $\beta 1$ weakened 3 hours after exposure (Group II), strengthened to the control group expression intensity at $24 \mathrm{~h}$ (Group III) post exposure and strengthened further to be higher than in the control group at $48 \mathrm{~h}$ (Group IV). The expression level of IL-10 rose slightly 3 hours after the exposure to ozone (group II), fell as the $24 \mathrm{~h}$ interval passed (Group III) to the control group level, and then rose slightly when observed at $48 \mathrm{~h}$ (Group IV) to the levels seen $3 \mathrm{~h}$ after exposure. In the liver samples, expression of IL-1 $\beta$ almost doubled in the time up to $3 \mathrm{~h}$ after exposure but declined slightly below the level in control animals after $24 \mathrm{~h}$. In the $48 \mathrm{~h}$ group, the expression level was the same as in the control rats. However, the expression of TNF- $\alpha$ rose only slightly in the $3 \mathrm{~h}$ group, fell at $24 \mathrm{~h}$ to the level present in the control animals, and rose in the last group to exceed this. The expression changes of NF- $\mathrm{BB}$ subunit genes differed markedly from what was seen in the lungs. The expression level decreased to slightly below the level in the control group but then increased past this by a large margin 24 and $48 \mathrm{~h}$ post exposure. 

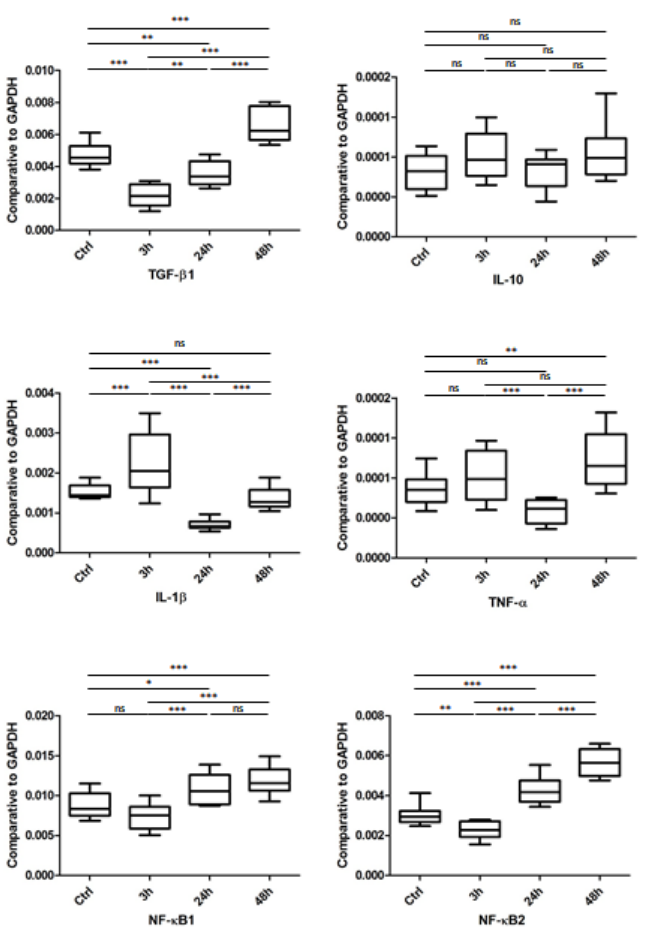

Fig. 2. Changes in interleukin expression in the liver. Ctrl - Group I (control); $3 \mathrm{~h}$ - Group II; 24h - Group III; 48h - Group IV. Significance levels are indicated with asterisks: $* \mathrm{P} \leq 0.05$; ** $\mathrm{P} \leq 0.01$; $* * * \mathrm{P} \leq 0.001$. Ns - not statistically significant

\section{Discussion}

Our results showed clearly that inhalational exposure to ozone at high concentration invokes an inflammatory state in the lungs, the organs directly exposed to it, but they also made apparent a response in an organ anatomically and functionally distant from the airways, namely the liver. The liver was purposely chosen for this study as an organ involved in the inflammatory response as the synthesiser of acute phase proteins, the blood concentrations of which increase (and sometimes decrease) in inflammation. Additionally, the liver is not associated with the lungs anatomically or functionally, unlike the heart.

What the mechanism of the systemic ozone influence is remains a matter of speculation. Ozone, being a very reactive molecule, can only directly affect tissues and cells to which it can have direct access. It is rapidly scavenged by other active molecules, such as polyunsaturated fatty acids abundant in cell membrane phospholipids (7) and free radical scavengers, such as glutathione or tocopherol. If ozone exerts a systemic influence, it must be via indirect action. A possible route is via the generation of active molecules, lipid peroxidation products being a relevant example, which reach various internal organs including the liver in systemic circulation. It is known that reactive oxygen species and lipid peroxidation products are involved in triggering the inflammatory response, being leukocyte chemoattractants. Lipid peroxidation products can derive from lung cell membrane phospholipids or be formed by peroxidation of polyunsaturated fatty acids present in the blood (13). Identification of these products and their production site needs further investigation.

Nuclear factor kappa-light-chain-enhancer of activated B cells, belonging to the class of rapid transcription factors, is among the first responders to harmful stimuli. It is the product of the expression of the two genes $N F K B 1$ and $N F K B 2$. This protein complex is present in the cytoplasm in the inactive state and its activation (via the canonical or non-canonical route) causes nuclear translocation where it upregulates the expression of a variety of genes (including its own inhibitor protein $\mathrm{I}-\kappa \mathrm{B})$ containing $\kappa \mathrm{B}$ target sequences. This mechanism does not require prior induction of $\mathrm{NF}-\kappa \mathrm{B}$ gene expression in order for it to work and does not need any particular mechanism of NF- $\kappa B$ gene regulation of expression. The proposed mechanism of $\mathrm{NF}-\kappa \mathrm{B}$ termination suggests that $\mathrm{I}-\kappa \mathrm{B}$ proteins expressed in response to $N F-\kappa B$ nuclear translocation enter the nucleus, bind to $\mathrm{NF}-\kappa \mathrm{B}$ bound to the $\mathrm{NF}-\kappa \mathrm{B}$ response sequence and translocate it to the cytoplasm (17). This would be an efficient NF- $\kappa B$ recycling process. However, our data show that both in the lungs (organs directly affected by ozone) and in the liver (an organ only indirectly affected) the expression of the NFKB1 and NFKB2 genes changes in a similar rhythm to that of the expression of TNF- $\alpha$ and IL-1 $\beta$. Clear differences regarding the measured extents of the expression level changes show that they are not due to the changes in the expression level of the reference gene. Very little is known about the mechanisms influencing NFKB1 and NFKB2 expression, and they must be elucidated in further studies.

The changes in the expression of pro-inflammatory cytokines TNF- $\alpha$ and IL- $1 \beta$ in the lungs are clearly associated with the irritating effect of the ozone. Their expression rose $3 \mathrm{~h}$ after exposure, but dropped dramatically to levels even lower than in the control animals $24 \mathrm{~h}$ after. It seems that the ozone action induced an anti-inflammatory response, which is made more plausible by the detected increase in TGF- $\beta$ expression $3 \mathrm{~h}$ after exposure and then gradual decrease $24 \mathrm{~h}$ and $48 \mathrm{~h}$ thereafter. What is interesting is that the expression of another anti-inflammatory interleukin, IL10, gradually diminished post-exposure. It can be posited that if the expression level of TNF- $\alpha$ and IL-1 $\beta$ decreased in an anti-inflammatory reaction, TGF- $\beta$ rather than IL-10 may be involved.

Our most striking findings are the changes in the expression of NF- $\mathrm{KB}$ and pro- and anti-inflammatory interleukins in the liver. It is well known that this organ is responsible for the production of many proteins associated with inflammation, the acute phase proteins among them. However, nothing is known about the inflammatory response of this organ due to the indirect influence of the inflammatory stimulus affecting lungs. The hepatic expression of NF- $\mathrm{B}$ was significantly higher 24 and $48 \mathrm{~h}$ after exposure. That was markedly different from the situation in the lungs where NF- $\mathrm{kB}$ 
expression rose then dropped rapidly. It is obvious that the mechanism influencing the NF- $\kappa \mathrm{B}$ expression in the liver must be different from the direct mechanism in lungs. The changes in the expression of pro-inflammatory interleukins were more pronounced for IL- $1 \beta$ than TNF- $\alpha$. This suggests that the liver reacts to the ozone action with the induction of an inflammatory state, albeit one invisible at the morphological level. It is known that IL-1 and IL-6 regulate the acute phase (14) and this may partially explain the changes in IL-1 expression in the liver.

Similar to the manner of the changes in the lungs, those in the expression of anti-inflammatory proteins were evidenced only for TGF- $\beta$, the expression of which was first attenuated conspicuously, then returned to approximately the normal level and then was augmented $48 \mathrm{~h}$ after exposure. This is suggestive of TGF- $\beta$ interference with the NF- $\kappa$ B pathway (4) also in the liver, influencing this organ's reaction to inflammatory stimulation.

This is our first attempt to study the relationship between the local and systemic actions of inhaled ozone. It also touches upon the largely unstudied aspect of changes in the gene expression of proteins (like NF- $\kappa \mathrm{B}$ and TGF- $\beta$ ) which are activated by a mechanism not associated directly with the induction of gene expression. As often happens, the results of the study generate more questions than answers. One of the aspects to study is the involvement of interleukin 6 (IL-6) in the liver response to inhaled ozone. A more classical approach should also be reprised and the peroxidation level measured as thiobarbituric acid reactive substances (TBARS). Another interesting problem planned for future investigation is the involvement of reactive oxygen species protective systems in the model used for this research.

Conflict of Interests Statement: The authors declare that there is no conflict of interests regarding the publication of this article.

Financial Disclosure Statement: The project was financially co-supported by the Ministry of Science and Higher Education under the "Regional Initiative of Excellence" programme for the years 2019-2022, project no. 010/RID/2018/19, amount of funding 12000000 PLN.

Animal Rights Statement: The authors declare that the experiments on animals were conducted in accordance with local Ethical Committee laws and regulations as regards care and use of laboratory animals (permission no. $80 / 2014 /$ DNT)

\section{References}

1. Clavo B., Santana-Rodriguez N., Gutierrez D., Lopez J.C., Suarez G., Lopez L., Robaina F., Bocci V.: Long-term improvement in refractory headache following ozone therapy. J Altern Complement Med 2013, 19, 453-458, doi: 10.1089/acm.2012.0273.
2. Đuricic D., Valpotić H., Samardžija M.: Prophylaxis and therapeutic potential of ozone in buiatrics: Current knowledge. Anim Reprod Sci 2015, 159, 1-7, doi: 10.1016/j.anireprosci.2015.05.017.

3. Elango N., Kasi V., Vembhu B., Poornima J.G.: Chronic exposure to emissions from photocopiers in copy shops causes oxidative stress and systematic inflammation among photocopier operators in India. Environ Health 2013, 12, 78, doi: 10.1186/1476-069X-12-78.

4. Freudlsperger C., Bian Y., Contag Wise S., Burnett J., Coupar J., Yang X., Chen Z., Van Waes C.: TGF- $\beta$ and NF- $\kappa$ B signal pathway cross-talk is mediated through TAK1 and SMAD7 in a subset of head and neck cancers. Oncogene 2013, 32, 1549-1559, doi: 10.1038/onc.2012.171.

5. Gold D.R., Damokosh A.I., Pope C.A., Dockery D.W., McDonnell W.F., Serrano P., Retama A., Castillejos M.: Particulate and ozone pollutant effects on the respiratory function of children in southwest Mexico City. Epidemiology 1999, 10, $8-16$.

6. Huth K.C., Saugel B., Jakob F.M., Cappello C., Quirling M., Paschos E., Ern K., Hickel R., Brand K.: Effect of aqueous ozone on the NF-kappaB system. J Dent Res 2007, 86, 451-456, doi: $10.1177 / 154405910708600512$.

7. Kafoury R.M., Pryor W.A., Squadrito G.L., Salgo M.G., Zou X., Friedman M.: Lipid ozonation products activate phospholipases A2, C, and D. Toxicol Appl Pharmacol 1998, 150, 338-349, doi: 10.1006/taap.1998.8418.

8. León O.S., Menéndez S., Merino N., Castillo R., Sam S., Pérez L., Cruz E., and Bocci V.: Ozone oxidative preconditioning: a protection against cellular damage by free radicals. Mediators Inflamm 1998, 7, 289-294, doi: 10.1080/09629359890983.

9. Li M.O., Wan Y.Y., Sanjabi S., Robertson A.K.L., Flavell R.A.: Transforming growth factor- $\beta$ regulation of immune responses. Annu Rev Immunol. 2006, 24, 99-146, doi: 10.1146/ annurev.immunol.24.021605.090737.

10. Lucas K., Maes M.: Molecular mechanisms underpinning laser printer and photocopier induced symptoms, including chronic fatigue syndrome and respiratory tract hyperresponsiveness: pharmacological treatment with cinnamon and hydrogen. Neuro Endocrinol Lett 2013, 34, 723-737.

11. Mittal S.K., Roche P.A.: Suppression of antigen presentation by IL-10. Curr Opin Immunol 2015, 34, 22-27, doi: 10.1016/j.coi.2014.12.009.

12. Ogata A., Nagahata H.: Intramammary application of ozone therapy to acute clinical mastitis in dairy cows. J Vet Med Sci 2000, 62, 681-686, doi: 10.1292/jvms.62.681.

13. Pryor W.A., Squadrito G.L., Friedman M.: The cascade mechanism to explain ozone toxicity: the role of lipid ozonation products. Free Radic Biol Med 1995, 19, 935-941, doi: 10.1016/0891-5849(95)02033-7.

14. Ramadori G., Christ B.: Cytokines and the hepatic acute-phase response. Semin Liver Dis 1999, 19, 141-155, doi: 10.1055/s2007-1007106.

15. Takeuchi C., Galvé R., Nieva J., Witter D.P., Wentworth A.D., Troseth R.P., Lerner R.A., Wentworth P.: Proatherogenic effects of the cholesterol ozonolysis products, atheronal-A and atheronal-B. Biochemistry 2006, 45, 7162-7170, doi: 10.1021/bi0604330.

16. Vaillant J.D., Fraga A., Díaz M.T., Mallok A., Viebahn-Hänsler R., Fahmy Z., Barberá A., Delgado L., Menéndez S., Fernández O.S.: Ozone oxidative postconditioning ameliorates joint damage and decreases pro-inflammatory cytokine levels and oxidative stress in PG/PS-induced arthritis in rats. Eur J Pharmacol 2013, 714, 318-324, doi: 10.1016/j.ejphar.2013.07.034.

17. Vallabhapurapu S., Karin M.: Regulation and function of NF- $\kappa B$ transcription factors in the immune system. Annu Rev Immunol 2009, 27, 693-733, doi: 10.1146/annurev.immunol. 021908.132641.

18. Ye J., Coulouris G., Zaretskaya I., Cutcutache I., Rozen S., Madden T.: Primer-BLAST: A tool to design target-specific primers for polymerase chain reaction. BMC Bioinformatics 2012, 13, 134, doi: 10.1186/1471-2105-13-134. 